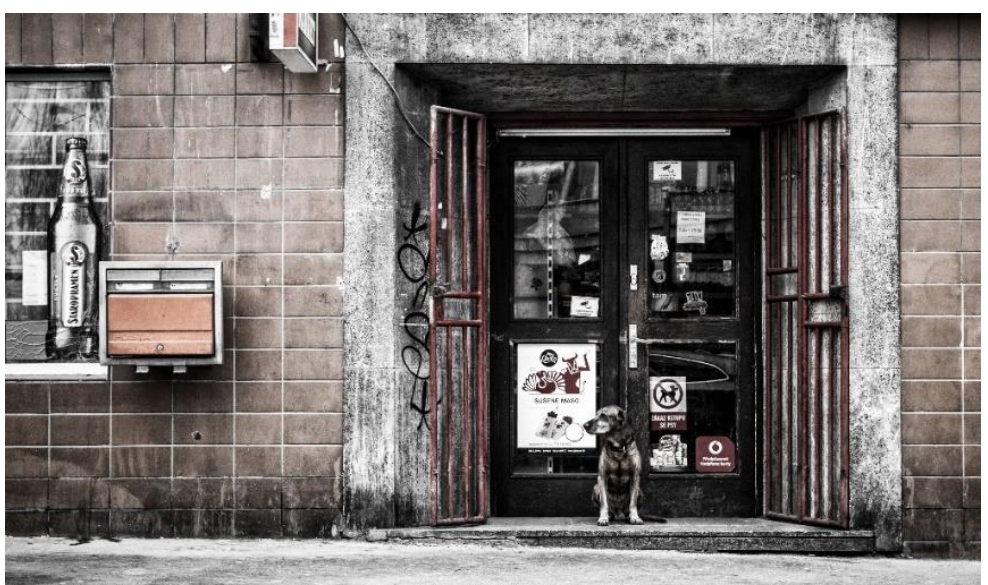

\title{
O encontro entre humanos, cães, ruas e arte: aproximações e experimentações conceituais
}

\author{
The encounter between humans, dogs, streets and art: conceptual approaches and \\ experimentations
}

\author{
Michele Fernandes Gonçalves ${ }^{1}$ \\ Ana Godoy ${ }^{2}$
}

\begin{abstract}
Resumo:
Este artigo propõe aproximações e experimentações conceituais a respeito do encontro entre humanos, cães e ruas. Explora-se a potência das relações que podem se estabelecer entre estes entes, no espaço público urbano, quando eles se encontram entre si através da arte. O objetivo, a partir do esgotamento do pensamento e da abertura à sensibilidade mediada pela arte, é provocar reflexões acerca das ordens discursivas que atualmente impõe-se aos entes de uma forma geral - e especificamente aos cães "abandonados" -, problematizar e redimensionar as relações entre eles e de todos com o habitar, e (des)identificar os cães "de rua" de categorias marginalizantes como a do abandono. A metodologia consiste de pesquisa bibliográfica abarcando autores contemporâneos dos campos da antropologia, da filosofia, da psicanálise e das artes.
\end{abstract}

Palavras-chave: Cães. Humanos. Ruas. Afetos. Potências. Arte.

\begin{abstract}
:
This article proposes some conceptual approaches regarding the encounter between humans, dogs and streets. The focus is to explore the power of the relationships established between these entities, in the urban public space, when they meet each other by the mediation of art. The goal is, through the exhaustion of the thinking and through the opening to the sensible, to evoke some reflection upon the discursive orders that currently impose themselves to entities as general and specifically to stray dogs; to question and resize the relationship between them and between all of them with the Heidegger's concept of dwelling; and to (un)identify the stray dogs from marginalized categories such as the abandonment. The methodology consists of bibliographic research on contemporary authors in the fields of anthropology, philosophy, psychoanalysis and the arts.
\end{abstract}

Keywords: Dogs. Humans. Streets. Affections. Powers. Art.

${ }^{1}$ Mestre em Sustentabilidade na Gestão Ambiental pela Universidade Federal de São Carlos, Campus Sorocaba e pesquisadora do grupo multiTÃO - prolifer-artes subvertendo ciências, educações e comunicações, Labjor/Unicamp. Endereço eletrônico: carpe mizinha@hotmail.com. Endereço postal: Rua Comendador Vicente do Amaral, 2290, apto 4C, Residencial Reserva do Bosque Ecoclub, Cep 18050-600, Sorocaba, São Paulo.

${ }^{2}$ Dra. em Ciências Sociais (PUCSP) e pesquisadora associada ao Grupo de Estudos e Pesquisas Anarquistas -GEPAN - da Universidade Federal da Paraíba - RFPB. É autora do livro A menor das ecologias (Edusp, 2008). Endereço eletrônico: ana.godoy@rocketmail.com . Endereço postal: Rua Tucuna, 1095/101, Pompéia, Cep: 05021-010, São Paulo, SP. 


\section{Introdução}

"Livro-me de uma tal subalternidade quando afirmo uma nova problemática, não por simples vontade narcisista de originalidade, mas porque afinei minha sensibilidade e pensamento com os imperativos de uma diferença que já está me forçando a sentir e pensar diferentemente".

(Luiz Orlandi. A morada do ente).

Este artigo aposta no encontro entre humanos, cães e ruas, e traça um campo problemático-conceitual acerca das relações que se estabelecem, ou não, entre os entes que habitam esses espaços de produção de subjetividades. $\mathrm{O}$ habitar, aqui, é entendido no sentido heideggeriano de "[...] constituir o ser do homem, [...] ser e estar sobre a terra, [...] ser na medida em que se habita” (HEIDEGGER, 1951), ou seja, cultivar e construir uma edificação de si mesmo no mundo. Para abarcar essa dimensão do habitar, o traçado desse campo envolve também outros encontros, entre humanos, animais e seu modo de estar, e entre pensares, concepções, sensibilidades, sensações, arte e vida. $\mathrm{O}$ caminho que leva a todos esses encontros se dá a partir do movimento - e do esgotamento - do pensamento sobre humanos e animais nas ruas, sobre a rua de humanos e animais, nos humanos com cães das ruas; dá-se, ainda, a partir do pensamento - e do esgotamento - que, com animais, pensa as ruas, os humanos e suas relações; que, por meio de humanos, pensa nas ruas com cães e nos cães da rua; e que, enfim, com e por meio das ruas, pensa o humano e o animal.

Pensar os cães "das ruas”, nas ruas, leva a uma incursão que é, ela mesma, um encontro: do limite do pensar, do pensar sobre o limite, do pensar sobre as relações que criamos, a partir dele e delas, com o mundo, e do pensar sobre os campos sensíveis que tais relações afetam e que por elas são afetados. O primeiro passo de tal incursão - a primeira seção do artigo, intitulada "O encontro do mal-estar e dos confins do pensamento" - é um convite ao cansaço, ao dissabor diante dos status segregacionistas entre humanos, animais - sendo os cães, nesse caso, o "tipo" animal a partir do qual se pensa - e seus espaços habitáveis. Os passos (seções) seguintes - "O encontro de naturezas e culturas", "Humano e animal, o encontro com o outro" e "Depois do abismo, o encontro entre possíveis" - são aqueles escolhidos para esgotar esse cansaço quando da observação de como as classificações e ordenações subjazem entes, coisas e funções. Tal esgotamento acontece pelo adentrar as discussões sobre naturezas e culturas (LÉVI STRAUSS, 1982, 1987; VIVEIROS DE CASTRO, 1996, 2002), sobre 
humanidades e animalidades (INGOLD, 1995; LESTÉL, 2011), homens e animais (DERRIDA, 2002), e sobre as diferentes perspectivas e campos conceituais que aproximam e afastam todos eles, e também pelo enveredar nos caminhos que as distinções, através das palavras e ordens do discurso (FOUCAULT, 1998, 2007), tomam em relação aos espaços em que se dão e em relação àqueles que neles vivem.

Esses encontros (do limite e do esgotamento do pensar) são, ao mesmo tempo, abstratos e concretos. Humanos e animais neles se constituem como categorias genéricas e específicas, na medida em que se referem tanto àqueles construídos ao longo da história do pensamento - o homem e o animal -, quanto àqueles sensíveis, fundados na materialidade: os humanos e os cães que, diariamente, habitam - moradores, passantes, transeuntes, circulantes - as ruas. A rua, por sua vez, é tanto aquela generalidade que define caminhos - aquele "conceito chave" do urbanismo - quanto a especificidade que abriga o movimento dos dias e das noites, que dá passagem aos fluxos, que permite o habitar pelos corpos, que é "[...] fator de vida das cidades" (JOÃO DO RIO, 1995, p. 4).

O último encontro deste artigo - que corresponde à seção nomeada "Encontro derradeiro pela multiplicidade", e que é também o último passo da incursão no pensamento e no esgotamento e o primeiro rumo à incursão na sensibilidade - é o encontro entre humanos e cães, estes últimos, aqueles que habitam as ruas - através da arte. Ele é aquele que diretamente se engaja na materialidade, ao convidar ao abandono da razão lógica e à invenção de um percurso que leva da exaustão do pensar às sensibilidades e potências que a prática do sentir pode alcançar. Ser material, aqui, significa relacionar-se com a vida pela conexão sensível, pelas sensações que o corpo experimenta no contato com o mundo por meio da criação artística. São as sensações a concretude deste último encontro, a aposta na abertura aos entes que tomam parte delas, nas possibilidades outras de se relacionar e de partilhar o universo sensível (RANCIÉRE, 2005).

A arte do encontro e o encontro pela arte são discutidos a partir da arte de rua. Eles partem dela e das questões que dela emergem e nela se afirmam. A arte é de rua e parte também do humano que na rua se constitui, que também a afirma como espaço de produção de relações amorosas e de permanência. A arte é de humanos e ruas e afirma nelas o encontro pela multiplicidade, pela sensibilidade que prolifera possíveis e que, fazendo-o, evidencia um espaço que é também o de todas as individualidades ali anteriormente emudecidas, uma rua de entes distintos a se cruzarem insistentemente, 
uma rua onde muitos deles - em especial cães e humanos - podem compartilhar espaços comuns de troca, de presença, de ser.

$\mathrm{O}$ encontro pela arte é aqui entendido como um descerramento do corpo à experimentação da potência da vida. Ele é concreto como força, mas demanda abstração como conceito, demanda ser discutido na amplitude da palavra que o comporta: a arte como vitalidade, energia, impulso, vigor que move e modifica existências. A particularização da experiência artística ${ }^{3}$, da arte como especificidade (em sua forma) e/ou como experimento (em sua ação), não poderia sustentar essa abertura sem facilmente se tornar seu próprio fechamento pela exemplificação, empobrecendo o campo de forças da criação artística. Interessa-nos, aqui, a arte que ultrapassa experimentos particulares de quaisquer tipos, os quais, se definidos e nomeados no início de um caminho que advém do esgotamento conceitual, e que é ainda inexplorado como experiência física original, correm o risco de se transformarem em meras ilustrações para o pensamento impedindo-nos de o esgotar e, assim, minando a tarefa a que nos propomos.

Os encontros desse artigo aqui se abrem, mas de forma alguma se encerram. Sua centelha de possíveis ganha apenas um esboço amplo do que pode vir a ser. Eles são os encontros, primeiramente, dos “outros de si mesmo"; também os da multiplicidade, do verdadeiramente outro, aquele que não se assemelha a nenhuma versão de nós; e, por fim, os da singularidade dos modos de ser com a unicidade dos modos de fazer. Aceitemos, então, esse convite à incursão pelo pensar e pelo sentir, e trilhemos o caminho dos encontros.

\section{$O$ encontro do mal-estar e dos confins do pensamento}

Este primeiro encontro se dá na exaustão causada pelo mal-estar oriundo da percepção de que um olhar excludente e dominante rege a compreensão e a construção das relações entre os entes, olhar este que parte de uma lógica maior que dita e estabelece os critérios de inclusão e exclusão aos quais estarão subordinados todos os viventes e suas convivências, entre si e com o mundo.

Esse mal-estar é aquele que observa que as classificações e distinções entre os entes, em particular entre humanos e animais, servem mais à construção de relações de

\footnotetext{
${ }^{3}$ Para um maior detalhamento do que aqui pontuamos, ver Gonçalves (2016), especialmente seções intituladas Conexões: arte, escrita e vida em movimento e Cães em caminho ou caminho de cães: reflexões.
} 
poder de uns sobre outros do que ao reconhecimento da singularidade e potência das diferenças entre ambos; que identifica que, mesmo dentro das divisões propostas pelos regimes de enunciação, alguns indivíduos ou classes de indivíduos possuem vantagens ou desvantagens em relação a outros, padrão este que se estabelece de acordo com parâmetros especialmente escolhidos para justificar e naturalizar tais exclusões; que percebe o utilitarismo e o egoísmo que desponta na convivência entre os entes especificamente definidos como humanos e animais de companhia; que vê, mesmo nas relações amorosas que figuram entre eles - em especial entre humanos e cães - como o condicionamento do olhar dos primeiros para os segundos dita as atitudes autoritárias e normativas daqueles sobre estes; que distingue, nessa relação, a determinação de subclasses bastante delimitadas, as quais recebem tratamentos bem específicos e diametralmente opostos; que verifica, dentre umas dessas subclasses - a dos "cães de rua" ou "cães abandonados" -, esse paradoxo intrínseco à sua classificação: o de que alguns animais são "bem mais animais" que outros; que constata, mesmo em alguns movimentos de luta pela emancipação ou proteção "animal", equívocos pungentes que acabam por aprisioná-los novamente dentro de parâmetros de vida ou sobrevivência igualmente limitadores.

O mal-estar é aquele que, enfim, “[...] nos invade quando forças do ambiente e a própria consistência da nossa subjetividade formam novas combinações, promovendo diferenças de estado sensível" (ROLNIK, 2002, p. 07). É a partir e através dele que chegamos ao limite: ao abalo de olhares pré-estabelecidos, à dúvida em relação às verdades que os definem, aos embaralhamentos por essas definições. A proposta, então, é partir desse limite e chegar aos confins do pensar sobre os entes e seu habitar, num quase perder-se por "encantos exóticos de outro pensamento" (FOUCAULT, 2007, p. ix); é duvidar das formas de compreensão das relações entre humanos, animais - em especial cães - e as ruas onde esses últimos, supostamente "abandonados", habitam; é encontrar outro tipo de abandono: o de formas únicas e dominantes do pensar - mais especificamente o da lógica maior que delimita territórios, exclui e aloca os entes em lugares pré-definidos e diz da rua como espaço indesejável para o habitar de cães e humanos -, e o de formas paliativas de auxílio a esses cães, formas estas que os retiram de situações "injustas" de vida na rua para dar-lhes condições supostamente mais dignas

\footnotetext{
4 "Cães abandonados" são aqui entendidos como os cães "sem dono", aqueles que habitam as ruas sozinhos ou na companhia de outros cães, aqueles que não se constituem em "animais de companhia" de qualquer humano, seja ele morador das ruas ou de qualquer outro tipo de "casa".
} 
em troca, contudo, de uma nova aniquilação, desta vez de sua potência de liberdade, um "[...] aniquilamento pela organização e exploração da sobrevida [...] fora de todas as normas supostas de vida própria aos animais assim exterminados na sua sobrevivência ou superpopulação mesmo" (DERRIDA, 2002, p. 52).

É sabido que as linguagens filosóficas podem arrumar o ser de um jeito e os entes de outro [...] Será que essa questão da morada do ente não conseguiria, por seus próprios méritos, arranhar a pele desse famoso ser? Essa questão não seria suficientemente forte para obrigarnos a uma reversão ontológica capaz de anarquizar o ser, uma reversão que [...] nos leve a pensá-lo tão somente em termos de uma diferenciação complexa, potenciando-se em todo e qualquer ente? (ORLANDI, 2004, p. 2 e 3).

O desafio do pensamento, a partir do arranhar da pele que leva ao encontro desses tantos abandonos - o dos cães nas ruas; o do julgamento de valor sobre essa condição; o das cristalizações conceituais sobre os animais, os humanos e os espaços habitáveis; e o do pensamento (sobre todos eles e inclusive sobre o próprio abandono) -, é atravessar e ultrapassar o mal-estar, transgredindo o estado lógico da razão que leva ao cansaço do pensar. A reversão ontológica, a anarquia do ente, é tomar esse cansaço como força, é utilizar-se do esgotamento para transformar o mal-estar numa sensibilidade sutil, que inaugure a ocasião de pensar os entes (e proliferar tais pensamentos) de formas outras, que oportunize conceber sua existência material, seu modo de vida, como um modo de, também e concomitantemente, habitar o mundo, que abra a ideia do habitar ao entendimento de um "existir sobre a terra" (HEIDEGGER, 1951), e que crie, por fim, possibilidades de se relacionar com os entes especificamente com os cães "de rua" - para além dos limites da experiência do pensamento, através de "forças que nos afetam e se fazem presentes em nosso corpo sob a forma de sensações" (ROLNIK, 2006, p. 3).

\section{O encontro de naturezas, culturas, humanidades e animalidades}

Este encontro é aquele que, a partir da exaustão e do mal-estar, adentra o esgotamento ao enfrentar as fronteiras do pensamento sobre o humano e suas relações com o que se costumou chamar, na sociedade ocidental, natureza. Ele explora as diferenças, semelhanças e destinações que estão no âmago dessas noções, e a despeito de responder à questão Afinal, o que separa naturezas, culturas, humanidades $e$ animalidades?, intui sugerir que há inúmeras respostas possíveis a depender da linha e 
do lugar a partir do qual se pensa, convidando, assim, ao esgotamento da presunção sobre a especialidade humana e à abertura de um espaço conceitual onde essas definições possam se dispor lado a lado.

Cultura e natureza são certamente umas das mais antigas dicotomias da história do pensamento ocidental. O legado evolucionista das cosmologias modernas sobre a natureza estabeleceu bases fortes na ideia de que ela é uníssona, fundando sua distinção na concepção de sua objetividade e postulando-a como "[...] garantida pela universalidade [...] dos corpos e da substância" (VIVEIROS DE CASTRO, 1996, p.116). Segundo esse pensamento, a natureza como fenômeno é anterior à ideia que se tem dela, de modo que todas as suas mudanças sempre se relacionam às suas dinâmicas, aos rumos que toma segundo as leis que a regem, mas nunca àquilo que a constitui como conceito. Já para a cultura, o caminho deu-se ao revés. Ela foi concebida como possibilidade de diferença entre os grupos humanos, como "[...] múltipla e subjetiva, gerada pela particularidade dos espíritos e significados" (VIVEIROS DE CASTRO, 1996, p.116), ou seja, como produção, como aquilo que "[...] singulariza os seres humanos enquanto suas relações entre si e com seu meio" (NUEMBERG; ZANELLA, 2003, p. 3). Em suma, o mesmo pensamento ocidental que considerou a natureza única fez da cultura, muitas.

A partir dos trabalhos de Claude Lévi-Strauss (1982, 1987), uma nova forma de pensar a relação entre natural e cultural foi inaugurada, forma esta que "[...] aboliu a necessidade de uma natureza única, dada e inata versus culturas construídas pelo esforço humano" (VELDEN; BADIE, 2011, p. 16). O pensamento do antropólogo francês abriu a possibilidade de que a relação entre natureza e cultura pudesse existir de diferentes formas em diferentes sociedades e de que ela pudesse ser "[...] tomada por suas singularidades [...] a partir do trabalho etnográfico" (VELDEN; BADIE, 2011, p. 16). Deste momento em diante, a cultura, que antes se subjazia de uma única forma ao mundo natural, passou a ser compreendida com certa autonomia sobre ele (NUEMBERG; ZANELLA, 2003).

Buscava-se, então, dar, à interpretação dos fenômenos culturais, outro patamar. De forma geral, principalmente a partir das contribuições darwinianas, pensava-se “[...] a cultura como via de adaptação dos humanos na garantia e manutenção de sua sobrevivência [...] algo subordinado ao biológico" (NUEMBERG; ZANELLA, 2003, p.2). A partir de Lévi-Strauss, entretanto, a cultura passou a ser aquela que buscava na natureza "[...] as categorias sobre as quais se assentaria para organizar o espectro social 
[...], mais a expressão [...] de valores simbólicos do que um instrumento de garantia de melhores condições de sobrevivência da espécie" (NUEMBERG; ZANELLA, 2003, p. 2 e 3). Ao invés de uma produção necessária à natureza, a cultura tornou-se uma espécie de organização estruturada que possuía, nela, seus homólogos. Havia uma correlação de relações entre o social e o natural, na qual a natureza tinha o papel de "[...] mediadora [...] da ordem simbólica [...], recurso para elaborar cognitivamente a diversidade humana" (NUEMBERG; ZANELLA, 2003, p. 2 e 3). Tratava-se, pois, de “[...] ordenar as diferenças para se chegar a uma correspondência" (DELEUZE; GUATARRI, 2012, p. 16) entre os grupos animais e humanos.

Se, por um lado, esse pensamento "[...] desempenhou um papel-chave na sedimentação de uma nova sensibilidade cultural" (VIVEIROS DE CASTRO, 2009, p. 195), por outro, do ponto de vista de um entendimento social, “[...] retomou a ideia das relações objetivas dos animais entre si em certas relações subjetivas do humano com o animal [...] gerando uma falha profunda que distribuiu correspondências sem semelhanças entre as duas" (DELEUZE; GUATTARI, 2012, p. 15 e 17). Desse ponto de vista, acabou por manter, de algum modo, a separação dos domínios da natureza e da cultura. Mesmo assim, considerando-se o encontro entre concepções distintas, entre as várias separações e aproximações desses domínios, a potência das contribuições de Levi-Strauss esteve justamente na mudança da posição a partir da qual se olhava para o binômio. A oposição que ainda se fazia era "[...] menos como um ponto de chegada do que como um instrumento para seguir adiante" (VIVEIROS DE CASTRO, 2009, p. 196), tendo um caráter sobretudo metodológico, de ferramenta de investigação de diferentes sociedades. Passou-se, assim, de uma “[...] oposição real para [...] uma antinomia inerente à reflexão da humanidade sobre sua própria condição [...] de uma universalidade objetiva, ou ontológica, [...] a uma universalidade subjetiva, ou antropológica" (VIVEIROS DE CASTRO, 2009, p. 196).

O encontro promovido por essa mudança de interpretação foi aquele com a desestabilização de noções bastante arraigadas na razão ocidental; entretanto, a concepção sobre o mundo natural e cultural ainda se fazia universalizante, na medida em que considerava que as correlações entre eles, embora culturais, davam-se da mesma forma em diferentes povos. A desuniversalização dessa e de outras visões acerca do binômio natureza-cultura ocorreu, principalmente, a partir das considerações de Eduardo Viveiros de Castro (1996, 2002), ao apontar que diferentes sociedades não 
opõem natureza e cultura da mesma maneira: "Não é que as sociedades diferentes das nossas não façam nenhuma diferença entre uma ordem humana e uma ordem não humana: simplesmente a diferença não faz exatamente a mesma diferença que entre nós” (VIVEIROS DE CASTRO, 2002, p. 196).

Para além de reconhecer as diferenças, Viveiros de Castro instaurou uma completa inversão destes valores na racionalidade ocidental em comparação aos povos ameríndios. A noção de perspectivismo proposta por ele colocou em pé de igualdade as categorias de interpretação de ambas as sociedades ao explicar que, na primeira, as concepções de natureza e cultura são multiculturalistas, ou seja, há uma continuidade física - somos todos, antes de tudo, animais -, e uma descontinuidade metafísica somos únicos e diferenciados pela originalidade do pensamento reflexivo (pela cultura) -, e que, já nas segundas, essas concepções são multinaturalistas, sendo a cultura objetiva e única e o espírito universal para cada povo, e a natureza subjetiva e múltipla e, os corpos, particulares (VIVEIROS DE CASTRO, 1996). A partir desta visão, os humanos puderam deixar de ser animais por primazia e ser, antes de tudo, humanos; assim como os animais puderam ser, também eles, humanos. A diferença estaria na maneira particular com que ambos viveriam sua condição natural, na "[...] forma manifesta de cada espécie [...] um mero envelope [...] a esconder uma forma interna humana" (VIVEIROS DE CASTRO, 1996, p. 117).

O perspectivismo, ao inverter papéis, mostrou que distintas noções moldam as relações humanas e animais e atribuiu a elas a mesma validade, provocando, assim como o estruturalismo, alterações profundas e definitivas nas concepções ocidentais aquelas que regem os pensamentos dominantes. Ao reestruturar e perspectivar a concretude de um mundo preestabelecido, ambos promoveram o encontro de diferentes lógicas - e de seus respectivos limites - e permitiram que a posição a partir da qual se olha para as relações entre natureza e cultura se alterasse de forma robusta. A partir desses dois movimentos, não se pôde mais falar em natureza e cultura no singular: elas passaram a ser plurais, naturezas e culturas.

Outro binômio antigo da história do pensamento é aquele relativo aos conceitos de humanidade e animalidade. Estes, assim como natureza e cultura, são constantemente indagados, embaralhados e reestruturados, na medida em que as relações entre os entes são destituídas de suas configurações teóricas e lançadas à sua materialidade iminente. Tim Ingold (1995) é um dos pensadores contemporâneos que propõe esse tipo de embaralhamento ao sugerir que a humanidade, como condição, não se restringe ao 
domínio do ser humano, como espécie. Utilizar a mesma palavra - humanidade - para distingui-los tanto como espécies animais - ou seja, que possuem uma condição física de animalidade - quanto como condição moral de ser pessoa - ou seja, de ter a condição humana - é, para ele, um equívoco. Ser pessoa - ter linguagem, racionalidade, autoconsciência e imaginação simbólica, as condições que possibilitam o exercício da moral -, não é, segundo o antropólogo, condição necessariamente imbricada numa classificação taxonômica única de Homo sapiens, ou seja, não é uma “[...] prerrogativa dos seres humanos [...] pode ser descrita sem pré julgar a extensão em que seres humanos biológicos ou outros animais de fato dela participam" (INGOLD 1995, pg. 10 e 13).

Segundo essa linha de pensamento, ao se tratar do humano e do animal, não necessariamente trata-se da animalidade e humanidade humana - no primeiro caso - $\mathrm{e}$ da animalidade animal, no segundo caso. Humanidade e animalidade atravessam humano e animal, não sendo estados do ser, mas condições que se cruzam. Podemos, assim, pensar numa "[...] humanidade animal, para além de uma animalidade humana" (INGOLD, 1995, p. 9), já que “[...] a humanidade se apresenta como um campo contínuo de variação [...] e toda e qualquer divisão desse campo é uma construção nossa, produto artificial de nosso pendor para a classificação e os estereótipos" (INGOLD, 1995, p. 4). Dessa maneira, ambas podem, mais que remeter a classificações insuficientes, precisar as relações que se mantêm entre essas classes.

Para Dominique Lestel (2011), por exemplo, a animalidade é determinada mais pelas relações que homem e animal estabelecem em conjunto do que pelas diferenças que os poderiam separar. Segundo o filósofo, essas relações, ao serem submetidas à história do homem, fizeram "[...] com que a animalidade evocasse limites de caráter taxonômico que se revelam fronteiras de caráter defensivo" (LESTEL, 2011, p. 24). Essas fronteiras tornam-se problemáticas porque focalizam as diferenças e não se abrem ao horizonte comum, à animalidade como "[...] aquela dimensão do humano que este oculta, notadamente, ao desqualificar seu corpo, seus desejos e seus afetos em relação a seu espírito ou à sua racionalidade" (LESTEL, 2011, p. 37). Para Lestel (2011), humanos e animais se definem sempre em termos de complementaridades em constante evolução, na medida em que formam associações fundadas em interesses recíprocos e trocas mútuas, as comunidades híbridas. A animalidade, assim, sempre se refere "[...] a 
esse vivente com o qual o compartilhamento de afetos é possível” (LESTEL, 2011, p. $37)$.

Tanto as contribuições do pensamento de Ingold (1995) quanto de Lestel (2011) sobre a animalidade e a humanidade atuam no sentido de estender esses conceitos para além das classificações ordinárias do humano e do animal, alterando, dessa maneira, os limites rígidos sobre os quais se estrutura o pensamento ocidental a respeito da vida e contribuindo, assim, para a abertura de outras possibilidades de olhar para ela.

\section{Homem e animal, o encontro com o outro}

Este encontro é aquele que, do esgotamento das definições de antigos binômios, parte para o limite dessas definições, o limite do pensamento, ou o pensamento no limite: o encontro com o outro, um "animal-outro". Porque nós (ou eu) e porque eles? são os questionamentos que impulsionam, aqui, ao abismo das distinções entre os entes, a partir do qual há a chance de repensar - e com sorte abandonar - estas posições.

Homem e animal são dicotomias que perseguem a razão ocidental desde a "criação do mundo" - aquela efetuada muito antes da Ciência, na grande maioria das religiões ocidentais. O filósofo francês Jacques Derrida (2002) discute tal separação ao perguntar-se, diante de um olhar animal para sua nudez e de sua vergonha para com ela e para com esse olhar: "Há muito tempo, pode-se dizer que o animal nos olha? Que animal? O outro" (DERIDA, 2002, p. 15). Para ele, pensar a nudez de si e do outro, um animal-outro, e antes, o pudor dessa nudez, é debruçar-se sobre as diferenças e distinções, os "próprios do homem":

Acredita-se geralmente que o próprio dos animais, e aquilo que os distingue em última instância do homem, é estarem nus sem o saber. Logo, o fato de não estarem nus, de não terem o saber de sua nudez, a consciência do bem e o do mal, em suma (DERRIDA, 2002, p. 17).

$[\ldots]$

Os homens deram-se essa palavra, o animal, concedendo-se ao mesmo tempo, para reservar-se, o direito à própria palavra, ao nome, ao verbo, ao atributo, à linguagem de palavras, enfim, [...] tudo o que seriam os próprios do homem [...] tudo aquilo de que seriam privados os outros em questão, estes outros que foram resumidos na palavra "o animal" (DERRIDA, 2002, p. 62).

Olhar para o que torna o homem próprio, singular, é se deparar com as figuras históricas de propriedade - e de separação - dele em relação aos demais entes. Os animais não estão nus porque nus já o são, mas o homem, este sim, está nu porque se viu capaz de existir na nudez, de ter a consciência dela e, antes, de conceituá-la. Ele só 
se torna homem, portanto, ao ser capaz dela (DERRIDA, 2002). É assim, através das figuras de propriedade, que o homem, para Derrida, constrói uma maneira de se apartar dos outros entes e vincula ao pensamento uma determinada forma de existir. Distanciase, pois, dos outros, os que não são homens, pela ausência e pela falta que há nos últimos, em detrimento da presença que agracia os primeiros: sobra razão, palavra, linguagem e capacidade de resposta a uns, e falta isso tudo aos outros.

É na nudez que se insere, para o filósofo, a razão lógica que funda as concepções dominantes de homem e animal: aquele que pensa, o singular definido "o homem" tem a ciência de si (de sua nudez) e, portanto, existe de uma maneira única, excepcional. A todos os outros, aos que "faltam", se lhes atribui uma existência sem muito sentido, ou antes, de sentido finito - e tal finitude é o sentido maior de existir do próprio homem -, uma existência genérica, o "singular genérico $o$ animal" (DERRIDA, 2002, p.64). As distinções, dessa forma, anunciam-se, de acordo com Derrida, no antes da nomeação e nominação: no artigo que define ao passo que generaliza, e, assim, aloca. Há, portanto, uma diferença construída quando se diz $o$ homem e $o$ animal. Ao dizer do primeiro, o artigo $o$ define, singulariza o homem como aquele que possui atributos únicos. Ao dizer do segundo, o mesmo artigo generaliza, engloba num mesmo substantivo próprio todos os outros viventes que não são homens: "Nesse conceito que serve para qualquer coisa, no vasto campo do singular genérico [...] seriam encerrados [...] todos os viventes que o homem não reconheceria como seus semelhantes" (DERRIDA, 2002, p. 64).

A divisão que se funda a partir dessa nomeação e daquela falta projetada - a da linguagem, da palavra, da razão - e traz, como aponta Derrida, consequências na construção das relações entre os entes denominados homem e animal. Ela faz do animal uma espécie de teorema e institui a divisão entre aqueles que podem ver e aqueles que só podem ser vistos: "[...] a relação de uma humanidade preocupada com seu próprio e ciumenta de si” (DERRIDA, 2002. p. 34 ). A falta, segundo ele, é tida por algumas escolas de pensamento como uma tristeza profunda, um luto melancólico reflexo de uma resignação muda: uma animalidade fadada à sujeição e ao mutismo de sua expressão (DERRIDA, 2002). Ela instaura e reivindica, de uma só vez, os próprios do homem e sua superioridade perante a vida animal. A partir daí, o assujeitamento é o caminho tristemente óbvio que se traça nessa relação, um caminho de uma violência naturalizada e naturalizante amparada por uma tentativa constante de dissimulação, ou 
de dissimular-se perante ela: uma “[...] organização em escala mundial do esquecimento ou desconhecimento da crueldade dessa relação" (DERRIDA, 2002, p. 52).

Como forma de combater a radicalidade dessa violência - mas, contudo, sem tocar em sua essência mesma, qual seja, a enunciação - outra lógica radical se institui, conforme discute Derrida: a do inegável. Ela abre a possibilidade da compaixão para com os animais - e funda na história a luta por seus direitos - mediante o deslocamento da questão original da falta para a inegabilidade (e passividade) da presença: se há muito que se ausenta - razão, linguagem, palavra -, há aquilo que se apresenta: a capacidade de sofrer, ou a incapacidade de não sofrer (DERRIDA, 2002). Não se trata mais, pois, do que os animais não têm ou não podem, mas do que padecem poder. Aloca-se, assim, a compaixão num novo tipo de tormento: uma "guerra a propósito da piedade" (DERRIDA, 2002, p. 57) e um utilitarismo de relação. Funda-se um comum entre homens e animais - o inegável do sofrimento - que, no entanto, afirma estes últimos novamente como outros, porém agora munidos de uma finitude compartilhada com o homem: a chance de não poder, "a angústia da vulnerabilidade" (DERRIDA, 2002, p. 55) perante a vida - a possibilidade da morte, em suma. A compaixão, desse modo, muda os termos da conversa, torna o animal próximo do homem, mas não questiona os fundamentos da diferença.

[...] se essas imagens são "patéticas", é também porque elas abrem pateticamente a imensa questão [...] do sofrimento, da piedade e da compaixão. E do lugar que é preciso dar à interpretação dessa compaixão, ao compartilhar do sofrimento entre os viventes, ao direito, à ética, à política que é preciso referir a essa experiência da compaixão. Pois o que ocorre, há dois séculos, é uma nova tribulação dessa compaixão (DERRIDA, 2002, p. 53).

Entretanto, para além da tristeza mediada pela falta, há, nesse mutismo animal que o assujeita e o violenta, segundo Derrida (2002, p. 42), “[...] uma queixa muda, mas audível por meio dos suspiros sensíveis [...] e que propõe uma inversão na essência da natureza": ao invés de triste porque muda, muda porque triste, ou seja, sem palavras porque assim foi denominada e, a partir de então, triste porque fadada a não ter o quê ou como dizer. Nesse sentido, “[...] ver-se dar seu próprio nome [e isso vale tanto para os animais como para o próprio homem] é deixar-se invadir pela tristeza" (DERRIDA, 2002, p. 42). Essa inversão de que fala Derrida é mais do que somente na essência da natureza, nessa suposta tristeza: é uma inversão na maneira de nomeá-la e de conceber suas relações, uma mudança na ordem do discurso que a denomina, ordem esta de tipo 
semelhante àquela que define os artigos ( $o$ homem e $o$ animal) e os pronomes (nós homens, eles animais).

[...] haveria os que viram, observaram, analisaram, refletiram o animal, mas nunca se viram vistos por ele [...] ou nunca levaram esse "ser visto" em consideração [...] não tomaram em consideração o fato de que o que chamam animal pudesse olha-los e dirigir-se a eles [...] com base numa origem completamente outra (DERRIDA, 2002, p. 32).

É devido a essa ordem discursiva que conjectura somente o ver, mas nunca o ser visto, que humano e animal, homens e cães, estão postos, no início e ao longo deste artigo, no problema do pensar, e do pensá-los no singular e no plural, e de tantas formas, e em relação consigo mesmos, um com o outro, e com seu habitar. Pois todas estas relações são fundadas, em primeira e última instância, pela maneira como os enunciamos e como acreditamos nas verdades postas pelos discursos que os definem (FOUCAULT, 1998). É justamente aí que se aventura o encontro - e o abandono - do limite mais extremo: as ordens do discurso.

\section{Depois do abismo, o encontro entre possíveis}

[...] os animais se dividem em: a) pertencentes ao imperador, b) embalsamados, c) domesticados, d) leitões, e) sereias, f) fabulosos, g) cães em liberdade, h) incluídos na presente classificação, i) que se agitam como loucos, j) inumeráveis, $\mathrm{k}$ ) desenhados com um pincel muito fino de pelo de camelo; l) et cetera, $\mathrm{m}$ ) que acabam de quebrar a bilha, n) que de longe parecem moscas (BORGES, 2007 apud FOUCAULT, 2007, p. ix).

A enigmática ordenação acima é um fragmento de um conto de Jorge Luís Borges (2007) intitulado O idioma analítico de John Wilkins, o qual cita certa enciclopédia chinesa que enuncia uma divisão dos animais. O encontro a que nos leva essa enciclopédia é aquele que nos alça dos limites das definições aos limites da própria linguagem que as enuncia. Na divisão proposta pela enciclopédia, o possível do conceito se encontra com o impossível do pensamento, com a completa confusão da linguagem, com o embaralhamento das lógicas usuais de ordenação dos entes através do emaranhamento das próprias palavras que as estabelecem. O fragmento supracitado traz um mal-estar difícil de vencer, pois que "[...] perturba todas as familiaridades do pensamento - do nosso; daquele que tem a nossa idade e a nossa geografia -, abalando todas as superfícies ordenadas e todos os planos que tornam sensata para nós a profusão dos seres" (FOUCAULT, 2007, p. ix). 
A enciclopédia incomoda porque desfaz a linearidade questionando os lugares dos entes, das coisas, das palavras e, em última análise, do real. A partir de sua taxonomia, não há mais hierarquia: culturas, naturezas, animalidades, humanidades, homens e cães estão juntos e aparecem lado a lado. Há um fracionamento e entrelaçamento dos nomes comuns, uma ruína da sintaxe que "[...] autoriza 'manter juntos' as palavras e as coisas" (FOUCAULT, 2007, p. xiii). O que acontece, a partir disso, é que “[...] a tábua de trabalho [...] que permite ao pensamento operar com os seres uma ordenação, uma repartição em classes, um agrupamento nominal pelo que são designadas suas similitudes e suas diferenças" (FOUCAULT, 2007, p. xii) é suspensa, de modo que "[...] não são os animais fabulosos que são impossíveis, pois que são designados como tais [...] o que transgride [...] todo o pensamento possível é [...] a série alfabética [...] que liga a todas as outras cada uma dessas categorias" (FOUCAULT, 2007, p. x). Desloca-se, assim, a maneira de organizar e classificar a natureza: cria-se um lugar desajeitado onde se colocam as coisas “[...] deitadas [...] dispostas em sítios a tal ponto diferentes que se torna impossível encontrar para elas um espaço de acolhimento, definir por baixo de umas e outras um lugar comum" (FOUCAULT, 2007, p. xiii). O que se perde com o texto de Borges, enfim, é a possibilidade de que exista um lugar real, para além da linguagem, onde esses seres possam se encontrar.

A divisão chinesa dos seres instiga-nos porque fende o limite mais extremo possível, o da ordem do mundo, e põe a linguagem como o lugar primeiro da criação da diferença. Ela fere, para além das estruturas cristalizadas de pensamento, a maneira como este se acostumou a se estruturar (e cristalizar): a lógica, a verticalidade, a hierarquia, a separação, a dicotomização. Mas em que medida, então, enfrentar este limite último - inevitavelmente acompanhado por todos os outros anteriormente aqui elucidados - serve para repensar as relações entre humanos, animais - especificamente cães - e as ruas por eles habitadas?

[...] a discussão merece começar quando se trata de determinar o número, a forma, o sentido, a estrutura desse limite [...] quando, ao invés de se perguntar se há um limite [...] pergunta-se: o que se torna um limite quando a fronteira não forma mais somente uma linha indivisível, mas muitas linhas? (DERRIDA, 2002, p. 60).

Decidir chegar ao limite é uma aposta de que partir dele pode levar à construção de um pensamento outro, além das cristalizações, e a um modo também outro de se relacionar com o mundo, para além do pensar. Há que se jogar no que de abissal têm os 
limites, pois eles exigem que se toque nos "alicerces da problemática filosófica do animal” (DERRIDA, 2002, p. 53). Há que se nutrir do insondável desses limites para então repensar, a partir de um lugar desprotegido, a partir das muitas linhas divisíveis e emaranhadas de vida, a existência e coexistência dos entes e seus atos de habitar, os quais, nesse caso, não se distinguem de seus próprios atos de existir (HEIDEGGER, 1951).

O conto de Borges ilustra bem os alicerces dessas problemáticas: deixa claro que o que define o conceito da diferença é, antes, a maneira de organizá-la e os pressupostos eleitos para torná-la verificável. Ao colocar seres muito diferentes lado a lado, ele adentra o limite do impossível, porém, quando elege, para a enciclopédia, um local originário autorizado a simbologias próprias do imaginário popular - a China - torna o limite possível (FOUCAULT, 2007). Isso significa que, se se define que seres fantásticos estão ao lado de cães em liberdade e que o "et cetera" não é mais aquele que termina uma ordenação qualquer, e se se elege parâmetros de verificação para tal mesmo que eles sejam "[...] uma pátria mítica [...], uma reserva de utopias" (FOUCAULT, 2007, p. xiv), torna-se essa ordenação possível. De maneira semelhante, se se definem os animais como mudos ou tristes ou subordinados, e se então se elegem pressupostos qualificáveis para justificá-los dessa forma, eles assim se encerram. Se, por outro lado, invertem-se as definições e se elegem outros parâmetros de verificação, então eles não mais serão reconhecidos na falta, no mutismo ou no assujeitamento: estarão abertos a possibilidades outras de existência. O mesmo ocorre também com o pensamento: se ele é definido como uma operação somente da razão, só haverá para ele esta servidão; se, contudo, é definido como abertura à sensibilidade - que não passa pela razão lógica mas pelo entendimento a partir do corpo, da sensação, dos sentidos - ele então é possibilidade de agir através dela: vira muitos e sem nenhuma hierarquia.

Se, por um lado, a enciclopédia chinesa confunde a ordem do mundo, por outro, "[...] faz cintilar os fragmentos de um grande número de ordens possíveis" (FOUCAULT, 2007, p. xiii) e ensina que elas - as ordenações - não necessitam de hierarquias, senão de reconhecimento das diferenças. O que passa a ser possível, a partir daí, é a existência de "[...] uma multiplicidade heterogênea de viventes [...] e das relações de organização e não organização entre os reinos cada vez mais difíceis de dissociar nas figuras do orgânico e inorgânico, vida e/ou morte” (DERRIDA, 2002, p. 61). Torna-se possível um modo de habitar que se vislumbre como "[...] o modo como 
os mortais são e estão na terra" (HEIDEGGER, 1951), o construir que "cultiva e edifica" (HEIDEGGER, 1951) a vida no mundo. Trata-se, pois, de tornar os entes muitos, e o habitar, apenas um para qualquer de suas condições de vida. Trata-se de fender o estrito dos limites não para desautorizá-los, mas para compor com eles uma proliferação de possíveis deles mesmos, os quais fragilizem as dicotomias, enfraqueçam os conceitos e façam caber, neles, outros. Antes de emprestar aos animais as palavras que eles supostamente não têm; antes de categorizar os modos de ser, viver e fazer, destituir, ao contrário, as separações e dicotomias, “[...] considerar a multiplicidade de limites e as estruturas heterogêneas" (DERRIDA, 2002, p. 87 e 88).

\section{Conclusão: Arte - encontro derradeiro pela multiplicidade}

\section{"[...] a arte começa talvez com o animal, ao menos com o animal que recorta um território e faz uma casa"}

(Gilles Deleuze e Félix Guattari. O que é a Filosofia?)

Após encontrar o mal-estar e o cansaço do pensamento sobre a exclusão, o assujeitamento e a separação de humanos e animais; após encontrar os desafios de pensar os limites das definições, das classificações e da linguagem que perpassam todos os entes; e após encontrar o limite e a estafa do próprio pensamento; há que se transformar a exaustão em algo além do niilismo: é preciso criar possibilidades para além das que já foram pensadas para a relação entre humanos e animais especificamente os cães "de rua". Não é mais possível que as soluções para o convívio entre eles estejam sempre condicionadas a dicotomias: ou à vida crua, marginal, "ilegal" e desrespeitada desses cães nas ruas, ou à captura física e subjetiva dessa vida, a ser "depositada" em conglomerados de anulação, transformada em corpos trancafiados em canis públicos ou privados. A vida desses animais pede mais que o sofrimento, a piedade ou o aprisionamento.

A proposta do encontro derradeiro é a de abrir, então, outras possibilidades para a relação entre esses entes. Ele já não se situa no cansaço dos limites, mas na sua transgressão, no pulsar singular que advém do esgotamento, na potência que aí pode haver. Esse encontro é com a multiplicidade, com os afetos do mundo, com um olhar que antevê os entes como reversões ontológicas de si mesmos, como pura pluralidade e diferenciação não hierarquizada. É o encontro pela sensibilidade, que não se fatiga, que 
ao contrário do mal-estar provoca e convida à criação, que se cria a ele mesmo como possibilidade impensada, inexplorada, e que se inventa como arte, na arte: encontra-a como força e inaugura relações sensíveis e afetos com o mundo (PORO, 2011).

Esse encontro é, primeiramente, do humano com a força de afetação da arte. Ela (a arte) ativa conexões inauditas e impensadas dele consigo mesmo, propulsões de sensibilidades que o forçam a estabelecer graus outros de relação com a vida e que lhe permitem apreende-la (a vida) em seu campo de forças, de afetos (ROLNIK, 2006). As sensações que ela causa, por serem inéditas e intraduzíveis, urgem à criação do que ainda não existe, tencionam as lógicas da percepção e ganham "[...] poder de interferência na realidade e de participação na orientação de seu destino" (ROLNIK, 2006, p. 3). É quando o pensamento arraigado na representação dos corpos e das existências - aquele que se cansa e se confunde, que chega ao fim de si mesmo e arrisca-se ao niilismo - lança-se rumo ao pensamento que parte justamente desse fim e chega às sutilezas que chamam para a experimentação sensível.

O encontro também é dos humanos com os cães através dessa força de afetação da arte. Ela (a arte) também ativa, na humanidade humana, conexões - antes emudecidas, silenciadas, apagadas pela razão lógica - com o outro que habita as ruas, o "cão-outro", e provoca a transgressão das hegemonias do pensamento, o qual, então, pode escapar às determinações, aos enrijecimentos e às ideias encerradas. Esse encontro faz desabrochar a singularidade que extrapola e caracteriza a alteridade e torna o outro parte de nós mesmos: “[...] dissolvem-se [...] as figuras de sujeito e objeto, e com elas aquilo que separa o corpo do mundo" (ROLNIK, 2006, p.10). A vida passar a ser possível para além das classificações: os entes podem ser apenas entes e podem se encontrar e se justapor lado a lado, como num conto chinês. Os territórios onde ela (a vida) se afirma proliferam e perdem qualquer obrigação de serem delimitados pela exclusão de uns ou outros entes neles, ao contrário, passam a ser a pura existência dos corpos aos locais onde perduram.

A concretude do encontro (de humanos, cães e arte) está justamente em tomar a rua como espaço onde pulsa a vida de todo ente, pulsar esse que traça tais territórios e constrói, neles, um habitar (HEIDEGGER, 1951), um local de ser, onde a condição material da existência (na rua) não se restringe ao viver (na rua), mas consolida-se no ato de nela demorar-se, de percorrê-la. O encontro pela arte cria, assim, a oportunidade de ultrapassagem da compreensão da rua como categoria que ou exclui pela inclusão - 
por um tipo de funcionamento que a determina como local impossível de permanência ou inclui pela exclusão - por um tipo de funcionamento que declara qualquer permanência como condição marginal. Ele transforma a rua em espaço de partilha, faz dela solo fértil da expressão de unicidades, duração no tempo em que nela se permanece, matéria de vida para qualquer ente que nela se demore e que nesse demorarse se edifique como ente vivo, pulsante.

A concretude também está na materialidade das sensações que a arte produz no corpo, arte que é criada na rua e que nela se mantém, arte feita ${ }^{5}$ pelo humano que na rua se detém, se demora, e nela propõe o encontro com os cães que também lá estão, arte que, “[...] como modo de expressão [...] de produção de linguagem [...] e de invenção de possíveis" (ROLNIK, 2006, p.02), chama a um encontro que escapa à razão lógica e afirma inúmeras possibilidades de existência: afirma a vida no habitar das multiplicidades.

As mudanças que o encontro pela arte, e com a arte, provoca no humano escutam as urgências das sensações, e são, somente nessa medida, éticas (ROLNIK, 2002; 2006). A ética, nesse caso, é “[...] antes o rigor com que se escuta e se afirma as diferenças do que um conjunto de regras tomadas como um valor em si para se chegar à verdade ou um sistema de verdades tomado como um valor universal" (ROLNIK, 2002, p.7). As verdades criadas a partir desse rigor, assim como as regras que se adotam ao criá-las, só têm valor “[...] tanto e quando são exigidas pelos problemas colocados pelas diferenças que nos desassossegam" (ROLNIK, 2002, p. 7). No encontro de humanos, cães, arte, e ruas, a ética é, pois, a da criação de configurações existenciais ainda

\footnotetext{
${ }^{5}$ A particularização do encontro com os cães através da produção de arte pelos humanos que na rua se demoram, habitam - no sentido heideggeriano do termo - não interessa a este artigo na medida em que tende a provocar o fechamento da amplitude da discussão que ele inicia - da arte como força de experimentação desse encontro - ao exemplificá-la com experimentos individualizados, experimentos pontuais que encerram a ideia do que a arte pode ser, da forma que ela pode ganhar. Entretanto, alguns experimentos - de encontros entre humanos e cães pela arte de rua, aquela que se faz na rua - foram, sim, realizados pelas autoras do presente artigo e estão detalhados em artigo ainda inédito, o qual parte do campo problemático aqui traçado e aprofunda a discussão da arte como potência de modificação da partilha sensível (RANCIÉRE, 2005) entre humanos e animais (cães em especial). Tal artigo resulta da segunda fase da pesquisa que originou a dissertação de mestrado intitulada Quando cães, humanos e ruas se encontram: pensamento, movimento e sensação por entre vidas, afetos, arte e palavras (GONÇALVES, 2016), e particulariza a experiência do encontro entre esses entes, experimenta e discute algumas das inúmeras maneiras pelas quais a arte pode aproximá-los pela sensação. Essa dissertação foi defendida em julho de 2016 no Programa de Pós-Graduação em Sustentabilidade na Gestão Ambiental da Universidade Federal de São Carlos - Campus Sorocaba, e toma a relação entre humanos e cães "de rua" para discutir possibilidades de outras concepções da sustentabilidade. O presente artigo é o resultado da primeira fase, da pesquisa teórico-conceitual realizada na referida dissertação, e privilegia, sobretudo, o campo problemático que tange as discussões filosófico-epistemológicas a respeito do humano e do animal - tomando os cães como entes que particularizam essa relação - e da produção de seus encontros e distanciamentos.
} 
impensadas para eles. A arte que efetua o encontro suscita a disjunção do que já está dado pelo pensamento sobre a condição dos entes nas ruas e propõe que se olhe novamente para eles, sem apriorismos de valor. Ela não é aquela que quer ter o controle sobre seus efeitos, e por isso, as mudanças que propõe são, também, estéticas, porque operaram pela suspensão de qualquer relação direta entre "[...] as formas sensíveis da produção artística e as formas sensíveis através das quais os espectadores [...] se apropriam dela" (RANCIÉRE, 2012, p. 56). A estética da arte que medeia o encontro de humanos e cães, assim, não visa à sensibilização através da vitimização desses últimos.

Além de ética e estética, a proposição do encontro com cães "de rua" pela arte de rua, feita na rua, é também uma ação política, pois pretende intervir na partilha que se faz do universo sensível e "[...] reconfigurar os âmbitos sensíveis nos quais se definem os objetos comuns” (RANCIÉRE, 2012, p. 59). Essa política é “[...] a prática que rompe a evidencia sensível na ordem 'natural' que destina os indivíduos [...] a certa maneira de ser, ver e dizer [...] numa [...] distribuição do visível e do invisível, da palavra e do ruído" (RANCIÈRE, 2012, p. 60), ou seja, é aquela que questiona, desafia e transgride a ordem estabelecida para as concepções sobre o mundo, o outro e o eu. A potência da criação artística - na rua, com cães "de rua" - nesse sentido, está na abertura à possibilidade de (RANCIÉRE, 2005) outros encontros sensíveis com o mundo, os quais oportunizem a esses e todos os outros entes serem contemplados como “outridades significantes” (HADAWAY, 2003).

O encontro pela arte não traz, necessariamente, resoluções sistemáticas para a ordem do discurso (FOUCAULT, 1979) que cria o abandono, mas produz, nele, o dissenso, “[...] a eficácia de uma desconexão [...] o conflito de vários regimes de sensorialidade" (RANCIÈRE, 2012, p. 59), o qual, na rua de humanos e cães, faz com que não seja necessário um acordo entre os discursos que querem afirmar o habitar dos cães nas ruas, ou os que querem negá-lo, mas que se imponha a coexistência dessa e de inúmeras outras possibilidades. Através do encontro, na rua, entre humanos, cães e arte em dissenso, faz-se possível a reconfiguração, pela sensibilidade, das lógicas ordinárias sobre eles projetadas, quais sejam: a da subordinação de uns aos outros; a da categorização de sua existência e de seus modos de ser e estar; a da representação (as figuras do humano e do animal) e da representatividade de direitos; e a das visibilidades (o visível e o invisível das ruas). Essa reconfiguração, potente por um tipo de criação e fazer artísticos que advém da sensibilidade, não corre o risco de recair no domínio da 
macropolítica de denúncia ou tentativa de conscientização ou 'politização' - no comum cotidiano do termo (ROLNIK, 2006). A tarefa da arte é distinta e irredutível a essa macropolítica: uma tarefa de suspensão, de desvio, de “[...] rasgar a cartografia do presente ao liberar a vida em seus pontos de interrupção devolvendo-lhe a força de germinação" (ROLNIK, 2006, p. 11).

Os caminhos propostos neste artigo para o encontro dos humanos com os cães "de rua" - o pensamento, o esgotamento, o limite e a sensibilidade - pretendem tornar impossível, para aqueles que se proponham a trilhá-los, pensar nesses e em todos os outros entes em termos de classificações fragmentárias e genéricas como natureza e cultura, humanidade e animalidade, homem e animal. A intenção é sugerir a possibilidade de que eles existam, ao contrário, na sua multiplicidade, na diferença que sirva não aos discursos excludentes e homogeneizantes, mas à vida, à existência que se inaugura justamente nessa diferença, na pluralidade, no coletivo, na força de multidão que lhes retira as formas constituídas e reintegra suas singularidades.

Tendo em vista o atual campo relacional hierárquico, autoritário e assujeitado que se estabelece entre humanos e demais entes, é urgente que se pense no plural, nos humanos e animais - e aqui, especificamos os cães "de rua" como um desses "tipos" animais - como entes que, ao se encontrarem e serem aptos a se afetar mutuamente, justamente aí se assemelham: não no sofrer, mas na heterogeneidade, na sensação, na sensibilidade. Esta seria, quiçá, uma abolição de todos eles como existências ensimesmadas, já que os entes não se separam entre si por limites indivisíveis, eles sequer existem como separação, mas apenas como “[...] 'viventes' cuja pluralidade não se deixa reunir numa única figura" (DERRIDA, 2002, p. 87), assim como a arte, esta que tampouco se deixa apreender numa única experiência particular.

$\mathrm{O}$ encontro pela arte é singular na medida em que é único, indeterminado $a$ priori, impossível de prever, mas não se restringe, contudo, a um único encontro, e nesse sentido é também múltiplo, construindo-se na riqueza e amplitude das possibilidades. O que tentamos, com sua proposição - aqui conceitual - é abrir, nessa problematização, a mesma dimensão que foi aberta, ao longo deste artigo, na incursão pelo pensamento e por seu esgotamento. De modo que a densidade da aposta e da proposta desse encontro se dá de forma semelhante àquela que se deu com o pensamento, pelo detalhamento, permitindo-nos afirmar que a experiência artística particular, concreta, deve ser tomada na imanência do que não se pré-determina (a 
experiência), sendo reenviada, portanto, à arte como acontecimento que não se esgota nas expressões particulares que o efetuam. O caminho pela arte não é então o do esgotamento, mas o da intensidade. É por isso que ele é sempre não sabido, se traça, sempre, na experiência, é, em suma, o da abertura de si, esta que está, sobretudo, na possibilidade de seguir em qualquer direção.

\section{REFERÊNCIAS}

BORGES, Jorge L. O idioma analítico de John Wilkins. In: Outras Inquisições. Trad. Davi Arrigucci Jr. São Paulo: Companhia das Letras, 2007.

DELEUZE, Gilles; GUATTARI, Félix. O que é a filosofia. Trad. Bento Prado Jr. e Alberto Alonso Muñoz. São Paulo: Ed. 34, 2010.

Paulo: Ed. 34, 2012.

DERRIDÁ, Jacques. O animal que logo sou. Trad. Fábio Landa. São Paulo: Ed. da Unesp, 2002.

FOUCAULT, Michel. Microfísica do poder. Trad. Roberto Machado. Rio de Janeiro: Graal, 1979.

A ordem do discurso. Aula inaugural do Collège de France, pronunciada em 2 de dezembro de 1970. Trad. Laura Fraga de Almeida Sampaio. São Paulo: Loyola, 1998.

As palavras e as coisas: uma arqueologia das ciências humanas. Trad. Salma Tannus Muchail. São Paulo: Martins Fontes, 2007.

GONÇALVES, Michele Fernandes. Quando cães, humanos e ruas se encontram: pensamento, movimento e sensação por entre vidas, afetos, arte e palavras. 2016. 135 p. Dissertação (Mestrado Profissional em Sustentabilidade na Gestão Ambiental) Programa de Pós-graduação em Sustentabilidade na Gestão Ambiental, Universidade Federal de São Carlos, Sorocaba, 2016.

HADAWAY, 2003. O Manifesto das Espécies de Companhia: cães, pessoas e a outridade significante. Trad. Sandra Michelli da Costa Gomes. Chicago: Prickly Paradigm Press, 2003. 39 p. Disponível em: <http://docslide.com.br/documents/omanifesto-das-especies-de-companhia-caes-pessoas-e-a-outridade-significante.html>.

HEIDEGGER, Martin. [Bauen, Wohnen, Denken] (1951). Viver, habitar, pensar. Trad. Marcia Sá Cavalcante Schuback. Conferência pronunciada por ocasião da "Segunda Reunião de Darmastad". Vortäge und Aufsätze, G. Neske: Pfullingen, 1954.

INGOLD, Tim. Humanidade e animalidade. Trad. Vera Pereira. Revista Brasileira de Ciências Sociais, v. 28, n. 10, p. 39-53, 1995.

JOAO DO RIO. A alma encantadora das ruas. Rio de Janeiro: Secretaria Municipal de Cultura/Departamento Geral de Documentação e Informação Cultural, 1995. Disponível em: <http://www.rio.rj.gov.br/dlstatic/10112/4204210/4101365/alma_ encant_ruas.pdf $>$. Acesso em: 10 ago. 2015. 
LESTÉL, Dominique. A animalidade, o humano e as comunidades híbridas. In: MACIEL, Maria Esther (org.). Pensar/escrever o animal: ensaios de zoopoética e biopolítica. Florianópolis: Editora da UFSC, 2011. 444p.

LÉVI-STRAUSS, Claude. As estruturas elementares do parentesco. Trad. Mariano Ferreira. Cap. 1. Petrópolis, RJ: Vozes, 1982.

1987.

O Pensamento Selvagem. Trad. Tânia Pellegrini. Campinas, SP: Papirus,

NUERNBERG, Adriano Henrique; ZANELLA, Andréa Vieira. A relação natureza e cultura: $O$ debate antropológico e as contribuições de Vygotski. Interação em psicologia, Curitiba v. 7, n. 2, p. 81-89, 2003. Disponível em: http://www.scielo.org.ar/pdf/ava/n19/n19a01.pdf. Acesso em: 10 ago. 2015.

ORLANDI, Luiz B. L. Morada do Ente. In: PÉLBART, Peter Paul; LINS, Daniel (Orgs). Nietschie e Deleuze: Bárbaros e Civilizados. São Paulo: Annablume, 2004. 248 pgs.

PORO. Intervalo, Respiro, Pequenos Deslocamentos: ações poéticas do Poro. In: CAMPBELL, Brígida; TERÇA-NADA!, Marcelo (Orgs). São Paulo: Radical Livros, 2011.

ROLNIK, Suely. Entrevista a Suely Rolnik. Despedirse del absoluto. Campo Grupal, Buenos Aires, ano 4, n. 35, p. 2-3, 2002.

. Geopolítica da cafetinagem. 2006. Disponível em: <http://www.pucsp.br/ nucleodesubjetividade/Textos/SUELY/Geopolitica.pdf>. Acesso em: 10 ago. 2015.

RANCIÈRE, Jacques. A partilha do sensível: estética e política. Trad. Mônica Costa Netto. São Paulo: Ed. 34, 2005.

Fontes, 2012.

O expectador emancipado. Trad. Ivone C. Benedetti. São Paulo: Martins

VELDEN, Felipe Vander; BADIE, Marilyn Cebolla. A relação entre natureza e cultura em sua diversidade: percepções, classificações e práticas. Avá, Revista de Antropología, [online], Posadas, n. 19, p. 00-00, 2011. Disponível em: <http://www.scielo.org.ar/ pdf/ava/n19/n19a01.pdf>. Acesso em: 10 ago. 2015.

VIVEIROS DE CASTRO, Eduardo. Os pronomes cosmológicos e o perspectivismo ameríndio. Maná, Rio de Janeiro, v. 2, n. 2, p. 115-144, 1996. Disponível em: $\langle$ http://www.scielo.br/scielo.php?script=sci_arttext\&pid=S0104-93131996000200005 $>$. Acesso em: Acesso em: 10 ago. 2015.

O nativo relativo. Maná, Rio de Janeiro, v. 8, n. 1, p. 113-148, 2002. Disponível em: <http://www.scielo.br/scielo.php?pid=S0104-93132002000100005 \&script=sci_arttext $>$. Acesso em: Acesso em: 10 ago. 2015.

Claude Lévi-Strauss por Eduardo Viveiros de Castro. Estudos avançados, São Paulo, v. 23, n. 67, p. 193-202, 2009. 


\section{Para citar essa obra:}

GONÇALVES, M. F., GODOY, A. O encontro entre humanos, cães, ruas e arte: aproximações e experimentações conceituais. In: RUA [online]. $\mathrm{n}^{\mathbf{0}}$. 22. Volume 2, p. 469 - 491 - ISSN 1413-2109/2179-9911 - Junho/2016. Consultada no Portal Labeurb Revista do Laboratório de Estudos Urbanos do Núcleo de Desenvolvimento da Criatividade.

http://www.labeurb.unicamp.br/rua/

Capa: PEICH, C. Disponível em: <https://unsplash.com/@chrispee>

Laboratório de Estudos Urbanos - LABEURB

Núcleo de Desenvolvimento da Criatividade - NUDECRI

Universidade Estadual de Campinas - UNICAMP

http://www.labeurb.unicamp.br/

Endereço:

LABEURB - LABORATÓRIO DE ESTUDOS URBANOS

UNICAMP/COCEN / NUDECRI

CAIXA POSTAL 6166

Campinas/SP - Brasil

CEP 13083-892

Fone/ Fax: (19) 3521-7900

Contato: http://www.labeurb.unicamp.br/contato 